\title{
ENSINO, PESQUISA, EXTENSÃO, INTERDISCIPLI- NARIDADE E HUMANIZAÇÃO PARA FORMAÇÃo EM SAÚDE
}

Enseñanza, investigación, extensión, interdiciplinaridad y humanización para la formación en salud

Teaching, research, extension, interdiciplinarity and humanization for health training

\section{Nathália Jorge Novais ${ }^{1}$, Juliana Sampaio ${ }^{2}$, Cláudia Batista Mélo ${ }^{3}$, Carmem Silvia Laureano Dalle Piagge ${ }^{4}$}

\section{RESUMO}

Este artigo tem como intuito apresentar alguns desafios e perspectivas para a formação em saúde a partir de três dimensões: a indissociabilidade entre ensino-pesquisa-extensão; a interdisciplinaridade como ampliação do olhar sobre o mundo; e as contribuições dos saberes indígenas para a humanização do cuidado. Trata-se de um estudo qualitativo por meio do relato de experiência do projeto Partejar Potiguara e das discussões do curso Humanização em Saúde da Universidade Federal da Paraíba. Essas dimensões inspiram a produção de conhecimentos científicos, repensam uma formação étnico-humanística e socialmente orientada, bem como problematizam o modelo biomédico, que compreendia o corpo como uma máquina e negligenciava os fatores culturais, psicológicos e sociais.

Palavras-chave: Formação em saúde; Ensino, pesquisa e extensão; Interdisciplinaridade; Humanização do cuidado.

\footnotetext{
1 Graduanda em Antropologia Social UFPB;

2 Doutora em Saúde Pública; Professora do Departamento de Promoção da Saúde - UFPB

3 Doutora em Engenharia Elétrica; Professora do Departamento de Clínica e Odontologia Social - UFPB.

${ }^{4}$ Doutora em Prótese Dentária; Professora do Departamento de Odontologia Restauradora - UFPB.
} 


\section{RESUMEN}

Este artículo tiene como objetivo presentar algunos desafíos y perspectivas de la educación para la salud desde tres dimensiones: la inseparabilidad de la docencia-investigación-extensión; la interdisciplinariedad como visión más amplia del mundo; y los aportes del conocimiento indígena a la humanización del cuidado. Se trata de un estudio cualitativo a través del relato de experiencia del proyecto Partejar Potiguara y las discusiones del curso Humanización en Salud de la Universidad Federal de Paraíba. Estas dimensiones inspiran la producción de conocimiento científico, repiensan una formación etno-humanista y socialmente orientada, así como problematizan el modelo biomédico, que entendía el cuerpo como una máquina y descuidaba factores culturales, psicológicos y sociales.

Palabras clave: Formación sanitaria; Docencia, investigación y extensión; Interdisciplinariedad; Humanización del cuidado.

\section{ABSTRACT}

This article aims to present some challenges and perspectives for health education from three dimensions: the inseparability of teaching-research-extension; interdisciplinarity as a broader view of the world; and the contributions of indigenous knowledge to the humanization of care. This is a qualitative study through the experience report of the Partejar Potiguara project and the discussions of the Humanization in Health course at the Federal University of Paraíba. These dimensions inspire the production of scientific knowledge, rethink an ethno-humanistic and socially oriented formation, as well as problematize the biomedical model, which understood the body as a machine and neglected cultural, psychological and social factors.

Keywords: Health training; Teaching, research and extensión; Interdisciplinarity; Humanization of care. 


\section{INTRODUÇÃO}

O ensino nos cursos de saúde se desenvolveu por meio do modelo biomédico fragmentado, predominante até meados do século XX, que concebia o corpo como uma máquina e negligenciava os fatores culturais, psicológicos, sociais e ambientais no processo saúde-doença (ALMEIDA, et. al. 2017). Frente às limitações desse modelo mecanicista, nas últimas décadas, as instituições de ensino, em consonância com os avanços no setor e com o papel regular do Ministério da Saúde e do Conselho Nacional de Saúde, passaram a refletir sobre a formação em saúde, buscando produzir novos conhecimentos e práticas de cuidado. Junto a este movimento, as escolas de saúde têm buscado produzir conhecimentos socialmente comprometidos, fruto de uma maior integração entre a comunidade acadêmica e a sociedade, bem como a readequação de processos de ensino-aprendizagem de graduandos, pós-graduandos e trabalhadores em serviço (BATISTA, 2013).

Segundo Sbeghen (2017), a reforma sanitária foi um marco importante para as problematizações sobre racionalidade biomédica, quando o próprio conceito de saúde ganhou novas dimensões e formas de compreensão.

Com o surgimento do Sistema Único de Saúde (SUS), o fenômeno da saúde passa a considerar essencial os condicionantes que transversalizam o processo de saúde e adoecimento, abrangendo as dimensões da vida social, econômica, histórica e cultural no processo de saúde e adoecimento no contexto brasileiro (BRASIL, 1990). Com isso, as instituições de ensino em saúde têm sido tensionadas, interna e externamente, a mudarem seus currículos formativos, com vistas a uma formação mais comprometida com a realidade social, a partir do desenvolvimento de uma consciência coletiva e, sobretudo, voltada à comunidade.

Desse modo, as diretrizes curriculares dos cursos de saúde mais atuais, a exemplo de Medicina e Odontologia, já propõem várias estratégias neste sentido, entretanto, as instituições de ensino apresentam dificuldades de efetivamente adequarem seus currículos a tais estratégias (SAMPAIO, et al. 2021). Contudo, são encontradas inúmeras dificuldades nas instituições federais de ensino superior para a mudança do currículo dos cursos de saúde, que tangem a didática docente, a experiência dos discentes no ensino, pesquisa e extensão, o diálogo interdisciplinar, a relação discente-docente e, consequentemente, o processo de ensino-aprendizagem (GONZÁLEZ; ALMEIDA, 2010). Assim, há uma infinidade de aspectos que influenciam na formação em saúde, tanto profissionalmente quanto na formação de cidadãos críticos.

Uma das estratégias utilizadas pelas instituições de ensino superior para mudança no currículo tem sido o desenvolvimento de tecnologias pedagógicas orientadas pela educação popular, compreendendo que a produção do conhecimento é um ato político e visa a transformação e a justiça social 
(ARAUJO, 2018). Dessa forma, a educação popular em saúde pauta uma série de questões sociais, inclusive a necessidade de produzir conhecimentos a partir das necessidades identificadas dentro e fora do ambiente acadêmico.

Este aspecto é fundamental quando levamos em consideração o projeto de silenciamento dos conhecimentos dos povos originários que, ainda hoje, vivenciam a colonialidade de seus saberes por meio do racismo estrutural e epistêmico que os desvaloriza e inferioriza (GROSFOGUEL, 2016). Gusman e colaboradores (2015) argumentam que tanto a colonização quanto a colonialidade retiraram a legitimidade a qual os povos tradicionais detinham, enfraquecendo os laços existentes. Por outro lado, os saberes científicos dominantes expandiram e mantiveram as desigualdades sociais com falsas ideologias hegemônicas do conhecimento. Isso resulta em práticas e condições precárias ao cuidado à saúde indígena e, sobretudo, em formação de profissionais não qualificados.

Tendo isso em vista, é importante que a universidade promova um ensino qualificado, apoiado na pesquisa e na extensão, visando a ruptura do saber teórico universalizante e hegemônico, ou seja, capaz de reconhecer, fortalecer e legitimar os saberes dos diversos povos que habitam este país (ARAUJO, 2018). Além disso, faz-se necessária a reformulação do currículo em saúde, de modo que sejam promovidos encontros interdisciplinares e desenvolvidas metodologias que favoreçam ao estudante protagonismo diante de sua formação e cidadania (ALMEIDA; BARBOSA, 2019).

Para tanto, o presente trabalho tem como objetivo apresentar alguns desafios e perspectivas para a formação em saúde socialmente orientada, capaz de formar profissionais com práticas mais humanizadas em saúde.

\section{METODOLOGIA}

Trata-se de um estudo qualitativo, a partir do relato de experiência de um projeto de pesquisa, ensino e extensão: Partejar Potiguara. Durante o ano de 2019, foram realizadas 18 viagens nas aldeias Forte, Lagoa do Mato, São Francisco, Laranjeira, São Miguel, Brejinho, Akajutibiró, Grupiuna, Tracoeira e Tramataia, nos municípios de Rio Tinto, Marcação e Baía da Traição, no estado da Paraíba. O projeto foi submetido e aprovado pelo Comitê de Ética (CAAE: 10145119.6.0000.8069).

As ações do projeto Partejar Potiguara foram desenvolvidas com o objetivo de conhecer e mapear os saberes tradicionais de assistência ao parto das parteiras Potiguara da Paraíba. Além disso, esse estudo é fruto também das discussões promovidas pelo curso de Humanização em Saúde, ofertado pelo Departamento de Clínica e Odontologia Social, do Centro de Ciências da Saúde, da Universidade Federal da Paraíba. 
Nesta conjuntura, as viagens ocorreram quinzenalmente com transporte disponibilizado pela Secretaria Estadual de Saúde e pela Universidade Federal da Paraíba. Durante a pesquisa, foram identificadas 7 parteiras e 9 mulheres engajadas no cuidado perinatal.

O projeto foi composto por uma equipe interdisciplinar, participando discentes e docentes dos cursos de Medicina, Cinema, Audiovisual, Radiocomunicação e Antropologia. Através do projeto, foi possível discutir a inserção sociopolítica das mulheres indígenas em suas comunidades, a relação delas com o sistema de saúde local, bem como conhecer suas relações com a espiritualidade e o sincretismo religioso. Além disso, foram ofertadas às indígenas mais jovens aulas de audiovisual, assim como foram realizadas exposições de vídeos sobre parteria e cultura indígena nas aldeias.

Em um primeiro momento, foram realizadas 3 rodas de conversas para conhecer as mulheres e parteiras da comunidade, uma vez que elas possibilitam um ambiente horizontal de diálogo. Segundo Sampaio e colaboradores (2014, p. 1300), as rodas de conversa são capazes de dar "liga a questões aparentemente separadas, a fim de que partes e todo sejam captados como facetas de um mesmo objeto, que em si mesmo é complexo e contraditório, duro e utópico: os condicionantes sociais e a realidade a ser (re)construída".

Nessas rodas de conversas, foram selecionadas 16 mulheres para entrevistas individuais. As entrevistas foram semiestruturadas para possibilitar a compreensão e o mapeamento das crenças, valores e comportamentos delas em momentos de partilhas mais individuais (JOVCHELOVITCH, BAUER, 2002). As entrevistas tinham como finalidade: a) traçar o perfil sociodemográfico das parteiras indígenas potiguaras; b) conhecer as técnicas tradicionais e biomédicas desenvolvidas pelas parteiras nas suas práticas de cuidado, e c) observar as práticas religiosas das parteiras indígenas potiguaras.

Após as entrevistas, as equipes foram divididas em duplas, compostas por discentes e docentes de diferentes cursos, para realizar vivências mais próximas ao cotidiano das mulheres. As visitas proporcionaram o conhecimento quanto à rotina das colaboradoras, suas casas, experiências cotidianas e relações familiares. Esses encontros possibilitaram uma maior conexão dos discentes com as vivências das parteiras, no intuito de romper com a perspectiva "observador e observada", tanto criticada na antropologia, ciências sociais e educação popular em saúde, favorecendo relações de confiança, troca e aprendizagem (OLIVEIRA, 2000).

As entrevistas e rodas de conversas foram gravadas e transcritas, enquanto as visitas foram registradas em diários de campo. Esses diários foram compartilhados durante as reuniões quinzenais da equipe, com finalidade de processar o vivenciado, fazer estudos teóricos e planejar coletivamente as demais ações do projeto. 


\section{RESULTADOS E DISCUSSÕES}

Para discutir as problemáticas da formação em saúde, foram analisadas as contribuições do Partejar Potiguara a partir de três dimensões: a) a indissociabilidade ensino-pesquisa-extensão; b) a interdisciplinaridade como ampliação do olhar sobre o mundo; e c) as contribuições dos saberes e práticas indígenas para a humanização do cuidado em saúde.

Backes (2005), Sbeghen (2017) e Almeida e Barbosa (2019) acreditam na interdisciplinaridade, como uma estratégia importante para promover diálogos sobre a atuação profissional em saúde, e na indissociabilidade da extensão, ensino e pesquisa, como forma de repensar a relação prática-teoria, contribuindo para a produção do saber científico. Além disso, esses autores ressaltam a importância de um espaço para reflexão crítica da realidade concreta, bem como para a formação de profissionais com práticas mais humanizadas. No projeto Partejar Potiguara foi possível experienciar e vivenciar a prática humanizada das parteiras, trazendo essas reflexões.

\section{A indissociabilidade ensino-pesquisa-extensão na formação universitária}

As instituições federais de ensino superior possuem três pilares estruturantes fundamentais de atuação: o ensino, a pesquisa e a extensão. Esses pilares são importantes no processo de formação, de produção de conhecimento e de transformação científico-social (ARAUJO, 2018; ALMEIDA; BARBOSA, 2019). Novais e colaboradores (2019) expõem o quão importante foi a articulação desses pilares nas ações do projeto Partejar Potiguara para a produção científica e o fortalecimento do saber tradicional indígena. De acordo com esses autores, o projeto Partejar Potiguara "colabora para interação entre a universidade e os saberes tradicionais, fazendo uma vinculação e troca de saberes que fortalece a construção do conhecimento" (NOVAIS, et. al. 2019, p. 9).

Nesse sentido, a extensão vem sendo reconhecida na formação nos últimos anos, tendo como perspectiva a ação social e a produção de diálogos entre a universidade e a comunidade (ARAUJO, 2018). Com essas vivências, a equipe Partejar realizou diferentes trabalhos que trataram da saúde, educação, política e outros âmbitos da comunidade indígena. Dessa forma, a extensão possibilitou que os discentes tivessem contato e conhecessem o saber, a realidade e as demandas sociais da população local, com vistas à produção de conhecimentos socialmente orientados. Além disso, assim como afirma Carneiro Cruz (2018, p. 16), a extensão promove o "fazer universitário que busca cotidianamente ser libertador, humanizante e emancipador", se contrapondo ao "modelo acadêmico tradicional através do desenvolvimento de experiências de trabalho social em meio ao concreto vi- 
vido da realidade e das questões humanas palpitantes do mundo na atualidade".

A equipe do projeto Partejar Potiguara identificou, na articulação do ensino, pesquisa e extensão, uma forma de discutir a formação universitária em saúde que, segundo Almeida e Barbosa (2019), está sendo repensada devido à expansão tecnológica e aos novos debates epistemológicos, resultando em uma reestruturação do currículo em saúde.

No Plano Nacional da Educação (PNE) de 2014-2024, existem estratégias para a integralização de pelo menos $10 \%$ dos créditos voltados à extensão durante a graduação (BRASIL, 2014). Trata-se da curricularização da extensão como forma de incentivar as universidades a pensarem em novas práticas e ações sociais junto às comunidades. Essa proposta observa a extensão como parte obrigatória da formação profissional, trazendo a importância da indissociabilidade entre a prática e a teoria na formação, que não existem uma sem a outra.

Assim, essa estratégia de curricularização da extensão, sobretudo em saúde, baseia-se nas propostas presentes nas Diretrizes Curriculares Nacionais (DCN), que propõem a formação de profissionais críticos e reflexivos, capazes de ofertar ações para o indivíduo e a comunidade (ALMEIDA, et al. 2017). Seguindo esse pensamento, o Partejar Potiguara desenvolveu suas ações de pesquisa e extensão articuladas com o ensino ofertado pela universidade, bem como em constante diálogo com as mulheres potiguaras. A equipe foi instigada a romper as fronteiras e paradigmas existentes, a questionar o conhecimento técnico e a analisar a realidade a partir de novas esferas, desenvolvendo, pois, habilidades inter e intrapessoais.

\section{A interdisciplinaridade como ampliação do olhar sobre o mundo}

Em articulação com a extensão universitária, uma equipe interdisciplinar contribui para reflexões de esfera política, social, cultural, educacional, científica e tecnológica, ou seja, contribui para a transformação social (BRASIL, 2018). Assim, no projeto Partejar Potiguara, o diálogo entre os cursos de saúde, comunicação e antropologia tiveram como finalidade a observação e análise das relações entre o sistema de saúde e as práticas de saberes tradicionais, as inserções sociopolíticas das parteiras Potiguaras e a relação das indígenas mais novas com esses conhecimentos. À vista disso, a "heterogeneidade do lugar de fala", o "posicionamento" de cada envolvido no projeto, o "enfoque" e a formação profissional dos sujeitos foram capazes de produzir reflexões sobre o cuidado humanizado na saúde, em especial, na assistência perinatal, e a valorização dos saberes tradicionais (ALMEIDA, et al. 2017).

O Partejar Potiguara estabeleceu diálogo entre as mulheres parteiras Potiguaras e os acadê- 
micos do Campus I, situado em João Pessoa, e do Campus IV, situado em Rio Tinto, pertencentes à Universidade Federal da Paraíba. Esse diálogo com as mulheres foi articulado tanto nas visitas, rodas de conversas e entrevistas, quanto na presença da equipe de pesquisa-extensão em outros momentos junto ao povo Potiguara (assembleias, rituais, datas comemorativas, reuniões, eventos etc.). Essa inserção permitiu que a equipe emergisse em meio às cosmologias potiguaras através da perspectiva dessas mulheres, observando as manifestações culturais e o modo como estas percebem e interagem com o mundo ao seu redor, na relação humano e não humano, suas crenças e seus valores.

A interdisciplinaridade articulada à extensão universitária em saúde resulta em relações mais dialógicas, com vínculos afetivos fortes e novas formas de acolhimento. Além disso, as ações de extensão universitárias interdisciplinares promovem a construção de novas práticas, sendo uma estratégia para a promoção da humanização do cuidado e a problematização do tecnicismo (BACKES, et al. 2005). Elas também qualificam todos os envolvidos para a atuação profissional e o reconhecimento das realidades sociais, sendo possível observar as desigualdades e estruturas de poder existentes na sociedade, bem como a diversidade cultural (ALMEIDA, et al. 2017).

A troca entre várias pessoas, com diferentes experiências, acúmulos práticos e teóricos, permitiu o compartilhamento de saberes do papel do audiovisual na preservação da cultura imaterial e na apropriação dos instrumentos audiovisuais para fins sociopolíticos, bem como na reflexão de novas práticas de saúde associadas às dimensões socioculturais e históricas e nas reflexões sobre os fenômenos de saúde-doença (SANTOS, et al. 2012), percebendo os outros aspectos que contribuem para a humanização do cuidado.

Deste modo, este diálogo permitiu o mapeamento dos saberes e práticas tradicionais de cuidado à saúde desse povo, sendo possível observar as singularidades existentes nos saberes da comunidade. Enquanto alguns discentes buscavam observar a cultura e os saberes indígenas a partir de seus processos e dinamicidade, outros encontravam-se em análises sobre a cultura visual, bem como nas rodas de conversas, trocas de experiências e busca dos significados, mobilizações e inserções das mulheres potiguaras.

Levando em consideração o processo de colonização e o silenciamento dos saberes, valores e práticas culturais potiguaras, a equipe buscou analisar as estratégias que as parteiras e outros detentores do saber (anciões) criaram para manter e fortalecer tais práticas. Exemplo disso é o diálogo

\footnotetext{
1 Cultura visual baseia-se no "visual como um lugar no qual se criam e se discutem significados" (p. 212) através da experiência cotidiana do visual. SARDELICH, M. E. Leitura de imagens e cultura visual: desenredando conceitos para a prática educativa (2006).
} 
que muitas mulheres, parteiras ou não, fazem com o saber científico, ao inserir-se nesses espaços.

Encontramos mulheres inseridas como agentes de saúde, técnicas em enfermagem e enfermeiras; na educação, como professoras e diretoras; na religião, como pajés; e na representação política, como caciques, vereadoras e até uma ex-prefeita, que tem o mérito de ter sido a primeira prefeita mulher indígena do país. Nesse sentido, os discentes de comunicação, saúde e antropologia buscaram os significados existentes nessas práticas e discutiram sobre suas percepções através de seus olhares, promovendo nas reuniões internas um ambiente rico de ensino e aprendizagem.

Para Almeida e colaboradores (2017), essa relação entre diferentes cursos é capaz de romper com a formação fragmentada e estereotipada, em especial dos cursos de saúde, pois promove a integração dos sujeitos, ou seja, "o contato com outras concepções e a desconstrução de possíveis estereótipos frente a determinadas profissões e áreas de atuação" (ALMEIDA, et al. 2017, p. 85).

As oficinas de audiovisual promoveram aulas em que as indígenas mais jovens puderam conhecer técnicas de gravação, fotografias, edição etc. O intuito dessas aulas foi o de apresentar um novo instrumento político, como forma de registrar a cultura imaterial e preservar os saberes de seu povo (MACÊDO, 2019). Nesse caso, foi identificada, na interdisciplinaridade, a possibilidade de se olhar para além dos horizontes, devido aos diferentes sujeitos envolvidos. Na avaliação de acadêmicos participantes do Partejar e das mulheres potiguaras, a oficina de audiovisual promoveu aulas diferentes, acolhedoras e singulares, na perspectiva de um ensino que "transforma a consciência, criando um clima de livre expressão que é a essência de uma educação em artes liberais verdadeiramente libertadoras" (BELL HOOKS, 2013, p. 63).

Nesse cenário, a interdisciplinaridade é entendida como um meio de se promover a humanização através do ensino, da pesquisa e da extensão, pois o diálogo entre diferentes áreas de conhecimento, assim como entre os saberes dos diferentes povos que aqui habitam, promovem novas discussões, capazes de transformar as práticas de cuidado. Afinal, cada sujeito (pesquisador e pesquisado) traz consigo, além de sua formação, seus percursos formativos próprios e experiências de vida, ampliando o diálogo da equipe e a reflexão das realidades sociais (ALMEIDA; BARBOSA, 2019). Dessa forma, esse projeto propõe a aplicação da interdisciplinaridade tanto para a comunidade Potiguara quanto para as distintas comunidades indígenas pesquisadas.

As ciências sociais e humanas, assim como a mudança dos currículos na área de saúde, promovem um diálogo que estimula a produção de conhecimentos científicos, discute os modelos de saúde, seus condicionantes e, sobretudo, contribui para a formação de profissionais mais competentes e compromissados com seu papel social (ALMEIDA, et al. 2017). 


\section{Contribuições dos saberes e práticas indígenas para a humanização do cuidado em saúde: perspectivas para a formação}

Durante as rodas de conversas e entrevistas, foram identificadas mulheres ativas em suas comunidades, inseridas em diferentes espaços comunitários, seja a educação, a saúde ou a representação política. Muitas mulheres atuam na área da saúde, como agentes de saúde indígena, técnicas de enfermagem e enfermeiras, com o mesmo objetivo de contribuir para o fortalecimento de suas práticas tradicionais a partir do diálogo com o saber biomédico (NOVAIS, 2019). Esses encontros foram cercados de sentimentos, afetos e partilha, recepcionados de forma positiva pelas mulheres potiguaras, e, nessa troca de conhecimentos, o Partejar foi aprendendo e se conectando com a comunidade, compreendo seus valores e tradições ancestrais, não só na saúde, mas em diversos âmbitos sociais.

Logo, foi gerado um laço de confiança e troca de saberes entre o projeto, as mulheres e as parteiras potiguaras, tornando possível conhecer as práticas de cuidado desenvolvidas por elas, que envolvem também o universo religioso e espiritual do povo.

O nascimento é um fenômeno que transversaliza o saber biomédico, social e cultural, cercado de símbolos e significados (FLEISCHER, 2011). Nas populações indígenas, o parto está correlacionado com os diferentes momentos de vida de cada pessoa. As técnicas de partejar sofrem, muitas vezes, preconceitos, mas devem ser vistas sob as diferentes óticas de cada povo indígena, devendo ser respeitadas as diversas culturas. Vale ressaltar que, em algumas culturas indígenas, o parto é tratado, em geral, de maneira humanizada e baseado em conhecimentos espirituais.

As reflexões críticas das ciências sociais e humanas proporcionadas pela extensão e pela equipe interdisciplinar do projeto contribuíram para o entendimento de conceitos importantes para a discussão sobre saúde, mais propriamente de saúde indígena. Os processos de deslegitimação dos saberes populares e tradicionais foram evidenciados, bem como a influência de dispositivos estruturais, como o biopoder e a colonialidade, para perpetuação da dominação do saber ocidental (GROSFOGUEL, 2016). Nesse processo de deslegitimar o conhecimento indígena, muitas parteiras sofreram a pressão dos postos de saúde e a desvalorização de seus saberes, assim, os seus dons passaram a serem vistos como senso comum pelas práticas biomédicas, sobretudo, pela sua própria comunidade, principalmente pelas indígenas mais jovens.

Outra reflexão importante que o projeto gerou foi referente ao racismo epistêmico. Segundo Grosfoguel (2016), o racismo epistêmico se fortalece e garante a invisibilização dos saberes culturais que não condizem com os valores eurocêntricos, inclusive no âmbito da saúde. A racionalidade biomédica é responsável pela imposição de formas "legítimas" de se descrever e entender o corpo 
como uma máquina, e, dessa forma, descrever também os processos sociais do desenvolvimento humano (FOUCAULT, 2008). Diferente da cultura indígena, no modelo ocidental, o parto é tratado como fenômeno que silencia as necessidades da parturiente.

Para a promoção de análises mais críticas acerca da realidade social, o reconhecimento da diversidade étnica-cultural, a ruptura dos estereótipos e a compreensão da saúde como um fenômeno complexo são fundamentais nos debates interdisciplinares, além da inclusão de outras racionalidades para se pensar a formação em saúde (SANTOS, et al. 2012). Afinal, as sobreposições, conflitos e negociações existentes entre os saberes tradicionais e o conhecimento biomédico fazem com que, ao mesmo tempo em que os detentores do saber tradicional sejam submetidos às práticas dominantes, resultem na produção de novas epistemologias de cuidado, no que é chamado de medicina contemporânea.

A equipe teve a oportunidade de compreender os fenômenos existentes na saúde e a forma como os profissionais percebem e agem sobre eles; além de conhecerem os saberes tradicionais e populares indígenas, produzindo reflexões sobre a cientificidade biomédica e colocando em prática novas formas de escuta, acolhimento e conhecimentos, tendo, como resultado, o desenvolvimento de práticas mais humanas de cuidado e de valorização dos saberes populares.

Por meio do diálogo, portanto, foi possível evocar a memória das mulheres indígenas para seus próprios saberes em meio às temporalidades e historicidades, com a finalidade de "despertar a memória, e relembrar o lugar de tradições e saberes que estão sendo apagados, a partir das sessões de cinema" (MACÊDO, 2019, p. 1). Esse diálogo entre os cursos e a comunidade indígena gerou reflexões sobre a construção do fenômeno saúde-doença, através de suas influências biológicas, psicológicas, culturais e sociais (GARCIA, et al. 2007; ALMEIDA, 2017).

\section{CONSIDERAÇÕES FINAIS}

A ruptura com o ensino tradicional em saúde ainda é um desafio, mas com os novos debates sobre a integração dos profissionais, a formação socialmente orientada e o olhar ao próprio conceito de saúde, torna-se possível formar profissionais éticos e com práticas mais humanizadas em saúde. Por meio do Partejar Potiguara, foram apresentadas importantes contribuições acerca da formação em saúde, sobretudo, para reflexão das estratégias presentes no projeto e sua implicação direta no processo de formação.

É evidente a importância da curricularização da extensão nos cursos de saúde para a formação de profissionais mais qualificados, articulados com a interdisciplinaridade de diálogo e a reflexão 
de práticas e saberes mais humanos. Assim sendo, a interdisciplinaridade existente nesse projeto de pesquisa-extensão contribui significativamente para discussões sobre a humanização do cuidado e valorização dos saberes tradicionais, sendo possível observar as singularidades das práticas desenvolvidas pelas parteiras Potiguaras. Como resultado dessa dialógica, temos a formação ética, filosófica e humana dos atores envolvidos.

Em suma, o projeto Partejar Potiguara contribui para a formação em saúde, uma vez que inspira a produção de conhecimentos científicos que transversaliza o fenômeno biológico, cultural, social e econômico, bem como repensa uma formação étnico-humanística e observa o cuidado de maneira integral.

\section{REFERÊNCIAS}

ALMEIDA, A. M. B. Contribuições das ciências sociais para profissionais em formação da área da saúde. SANARE, Sobral, v. 16 Suplemento n. 1, p.82-88, 2017.

ALMEIDA, S. M.; BARBOSA, L. M. Curricularização da Extensão Universitária no Ensino Médico: o Encontro das Gerações para Humanização da Formação. Revista Brasileira de Educação Médica, p. 672-680, 2019.

ARAUJO, R. S. Extensão universitária: aspectos histórico-conceituais e o desvelar de outra possibilidade teórico-metodológica a partir da educação popular. In: CARNEIRO CRUZ, P. J. S. et al. (Orgs.). Vivências de extensão em educação popular no Brasil: extensão e formação universitária: caminhos, desafios e aprendizagens. João Pessoa: Editora do CCTA, 2018.

BATISTA, C. B. Movimentos de reorientação da formação em saúde e as iniciativas ministeriais para as universidades. Barbarói, Santa Cruz do Sul, n. 38, p. 97-125, jan./jun. 2013.

BACKES, D. S. et. al. A construção de um processo interdisciplinar de humanização à luz de Freire. Texto Contexto Enferm, v. 14, n. 3, p. 42-434, jul. /set., 2005.

BRASIL. Lei n. ${ }^{\circ}$ 8.080. 19 set. 1990. Dispõe sobre as condições para a promoção, proteção e recuperação da saúde, a organização e o funcionamento dos serviços correspondentes, e dá outras providências. 1990 .

BRASIL. Lei 13.005, de 25 de junho de 2014. Plano Nacional de Educação - PNE e outras providências. Disponível em http://www.planalto.gov.br/ccivil_03/_Ato2011-2014/2014/Lei/L13005. htm. Acesso em: 20 nov. 2020.

BRASIL. Resolução CNE/CES 7/2018. Diretrizes para a Extensão na Educação Superior Brasileira. Diário Oficial da União, Brasília, 18 dez. 2018, Seção 1, p. 49 e 50. Disponível em: https:// 
www.in.gov.br/materia/-/asset_publisher/Kujrw0TZC2Mb/content/id/55877808. Acesso em: 20 nov. 2020.

CARDOSO DE OLIVEIRA, R. A antropologia e a "crise" dos modelos explicativos. In: O trabalho do antropólogo. 2. Ed. Brasília. São Paulo: Editora UNESP, 2000.

CARNEIRO CRUZ, P. J. Extensão popular: um movimento, um mosaico diverso de práticas e uma concepção para a reorientação do fazer universitário tradicional. In: CARNEIRO CRUZ, P. J. S. et al (Orgs.). Vivências de extensão em educação popular no Brasil: extensão e formação universitária: caminhos, desafios e aprendizagens. João Pessoa: Editora do CCTA, 2018.

FLEISCHER, S. Parteiras, buchudas e aperreios: uma etnografia do atendimento obstétrico não oficial em Melgaço, Pará. Belém: Editora Paka-Tatu, 2011.

FOUCAULT, M. Nascimento da Biopolítica. São Paulo: Martins Fontes, 2008.

GARCIA, M. A. A. et. al. A interdisciplinaridade necessária à educação médica. Revista Brasileira de Educação Médica, Rio de Janeiro, v. 29, n. 1, p. 147-155, 2007.

GONZÁLEZ, A. D.; ALMEIDA, M. J. Ativação de mudanças na formação superior em saúde: dificuldades e estratégias. Revista Brasileira de Educação Médica, p. 238-246; 2010.

GROSFOGUEL, R. A estrutura do conhecimento nas universidades ocidentalizadas: racismo/sexismo epistêmico e os quatro genocídios/epistemicídios do longo século XVI. Soc. estado, v. 31, n. 1, 2016.

GUSMAN, C. R. et al. Inclusão de parteiras tradicionais no Sistema Único de Saúde no Brasil: reflexão sobre desafios. Rev. Panam Salud Public, v. 3, n. 4, p. 365-370, 2015.

HOOKS, BELL. Ensinando a transgredir: a educação como prática de liberdade. São Paulo: Editora WMF Martins Fontes, 2013.

JOVCHELOVITCH, S.; BAUER, M. W. Entrevista narrativa. In: BAUER, M.; GASKELL, G. Pesquisa qualitativa com texto, imagem e som: um manual prático. Petrópolis, RJ: Vozes, 2002.

MACÊDO, A. C. C. O papel do audiovisual no Projeto de extensão Partejar. In: VII Seminário Nacional Gênero e práticas culturais. Anais eletrônicos - trabalhos completos. João Pessoa, 2019. Disponível em: https:/viisngpc.files.wordpress.com/2020/04/gt1-ana-caroline-costa-macedo_.pdf. Acesso em: 20 nov. 2020.

NOVAIS, N. J. et al. Protagonismo feminino Potiguara: representatividade e luta. In: VII Seminário Nacional Gênero e práticas culturais. Anais eletrônicos - trabalhos completos. João Pessoa, 2019. Disponível em: https://viisngpc.files.wordpress.com/2020/04/gt9-nathalia-jorge-novais-fer- 
nanda-monteiro-de-abreu-lima-juliana-sampaio_.pdf. Acesso em: 27 ago. 2020.

SAMPAIO, J. et al. Limites e potencialidades das rodas de conversa no cuidado em saúde: uma experiência com jovens no sertão pernambucano. Comunicação, Saúde, Educação, v. 2, p. 12991312, 2014.

SAMPAIO, J. et al. Partejar Potiguara: Um olhar para os desafios do ensino superior público de qualidade, a partir da Extensão Universitária. In: LIMA, C. P. (Org.). Educação em debate: em defesa da dimensão pública da educação brasileira. 1ed. Marília: Lutas Anticapital, 2021.

SANTOS, A. C. B. et. al. Antropologia da saúde e da doença: contribuições para a construção de novas práticas em saúde. Rev. NUFEN, v. 4, n. 2, São Paulo, dez./2012.

SARDELICH, M.E. Leitura de imagens e cultura visual: desenredando conceitos para a prática educativa. Educ. rev, n. 27, 2006, p. 203-219.

SBEGHEN, E.P.D; et. al. O processo de ensino e aprendizado na área da saúde humana para atuação no sistema único de saúde. Unoesc \& Ciência - ACHS Joaçaba, v. 8, n. 2, p. 211-218, jul. /dez. 2017. 